Table 1. Achievement of Key Outcomes Across PsA Manifestations at Week 104 Among TNF-IR and TNFi-Naive Patients Treated With SEC

\begin{tabular}{|c|c|c|c|c|c|c|c|c|c|c|}
\hline \multirow[b]{2}{*}{ Outcomes, n/M (\%) } & \multicolumn{2}{|l|}{ SEC $300 \mathrm{mg}$} & \multicolumn{2}{|l|}{ SEC $150 \mathrm{mg}^{\mathrm{a}}$} & \multicolumn{2}{|c|}{ SEC $150 \mathrm{mg}$ No Load } & \multicolumn{2}{|c|}{ PBO-SEC $300 \mathrm{mg}$} & \multicolumn{2}{|c|}{ PBO-SEC $150 \mathrm{mg}^{\mathrm{c}}$} \\
\hline & $\begin{array}{l}\text { TNFi-naive } \\
\mathrm{n}=154\end{array}$ & $\begin{array}{l}\text { TNF-IR } \\
\mathrm{n}=68\end{array}$ & $\begin{array}{l}\text { TNFi-naive } \\
\mathrm{n}=153\end{array}$ & $\begin{array}{l}\text { TNF-IR } \\
\mathrm{n}=67\end{array}$ & $\begin{array}{l}\text { TNFi-naive } \\
\mathrm{n}=157\end{array}$ & $\begin{array}{l}\text { TNF-IR } \\
\mathrm{n}=65\end{array}$ & $\begin{array}{l}\text { TNFi-naive } \\
\mathrm{n}=109\end{array}$ & $\begin{array}{l}\text { TNF-IR } \\
n=44\end{array}$ & $\begin{array}{l}\text { TNFi-naive } \\
\mathrm{n}=114\end{array}$ & $\begin{array}{l}\text { TNF-IR } \\
\mathrm{n}=39\end{array}$ \\
\hline TJC/SJC resolution & $51 / 140(36.4)$ & 19/51 (37.3) & 46/136 (33.8) & $11 / 46(23.9)$ & $53 / 125(42.4)$ & $14 / 43(32.6)$ & $40 / 90(44.4)$ & $11 / 31$ & $32 / 96(33.3)$ & $10 / 28$ \\
\hline Resolution of dactylitis & $42 / 48(87.5)$ & $11 / 16(68.8)$ & $37 / 43(86.0)$ & $16 / 19(84.2)$ & $56 / 62(90.3)$ & $11 / 13(84.6)$ & $35 / 41(85.4)$ & $5 / 7(71.4)$ & $30 / 33(90.9)$ & $10 / 12(83.3)$ \\
\hline Resolution of enthesitis & $70 / 88(79.5)$ & $22 / 30(73.3)$ & $70 / 85(82.4)$ & $24 / 32(75.0)$ & $50 / 69(72.5)$ & $16 / 26(61.5)$ & $37 / 50(74.0)$ & $12 / 17(70.6)$ & $39 / 56(69.6)$ & $14 / 20(70.0)$ \\
\hline mNAPSI75 & $61 / 73(83.6)$ & $15 / 26(57.7)$ & $66 / 76(86.8)$ & 16/23 (69.6) & $61 / 80(76.3)$ & $13 / 18(72.2)$ & $42 / 51(82.4)$ & $13 / 17(76.5)$ & $34 / 64(53.1)$ & $7 / 14$ \\
\hline PASI100 & $34 / 68(50.0)$ & $14 / 29(48.3)$ & $41 / 85$ & $5 / 19$ & $33 / 73(45.2)$ & $4 / 18$ & $23 / 45(51.1)$ & $9 / 18$ & $19 / 46(41.3)$ & $\begin{array}{l}(50.0) \\
6 / 13\end{array}$ \\
\hline & & & & (26.3) & & (22.2) & & $(50.0)$ & & $(46.2)$ \\
\hline
\end{tabular}

IR, inadequate responder; M, number of evaluable patients; mNAPSI, modified Nail Psoriasis Severity Index; PASI, Psoriasis Area and Severity Index; PBO, placebo; SEC, secukinumab; TJC/SJC resolution, 0 tender/swollen joints; TNFi, tumor necrosis factor inhibitor.a Includes 53 TNFi-naive and 23 TNF-IR patients with dose escalation.b Includes 58 TNFi-naive and 19 TNF-IR patients with dose escalation.c Includes 40 TNFi-naive and 12 TNF-IR patients with dose escalation.

Background: The goal of treating psoriatic arthritis (PsA) is to achieve very low disease activity or remission across disease manifestations. In the phase 3 FUTURE 5 study (NCT02404350), patients receiving secukinumab (SEC) demonstrated sustained clinical improvements across PsA manifestations through Week 104. ${ }^{1}$ However, the effect of previous tumor necrosis factor inhibitor (TNFi) exposure on achievement of remission across PsA manifestations was not explored. Objectives: To report exploratory efficacy analyses of SEC at Week 104 on stringent endpoints across PsA manifestations in patients who were TNFi naive or inadequate responders (TNF-IR).

Methods: Patient data from FUTURE 5 were stratified by previous TNFi exposure and analyzed by treatment arm. At Week 104, patients received SEC 300 or $150 \mathrm{mg}$ with subcutaneous loading dose (LD), SEC $150 \mathrm{mg}$ without LD, or had received placebo up to Week 16 and were switched to SEC 300 or $150 \mathrm{mg}$ between Weeks 16 or 24 based on tender and swollen joint count response. Patients with suboptimal clinical response to SEC $150 \mathrm{mg}$ could escalate to SEC $300 \mathrm{mg}$ after Week 52 per investigator judgment. ${ }^{2}$ Exploratory efficacy analyses at Week 104 included resolution of TJC/ SJC ( 0 tender/swollen joints), resolution of enthesitis and dactylitis, $75 \%$ improvement in the modified Nail Psoriasis Severity index (mNAPSI75), 100\% improvement in the Psoriasis Area and Severity Index (PASI100), very low disease activity (VLDA), and Disease Activity in Psoriatic Arthritis (DAPSA) remission. Descriptive statistics are provided for each endpoint using an observed-case approach.

Figure. Proportion of Patients Achieving (A) VLDA and (B) DAPSA Remission at Week 104

A

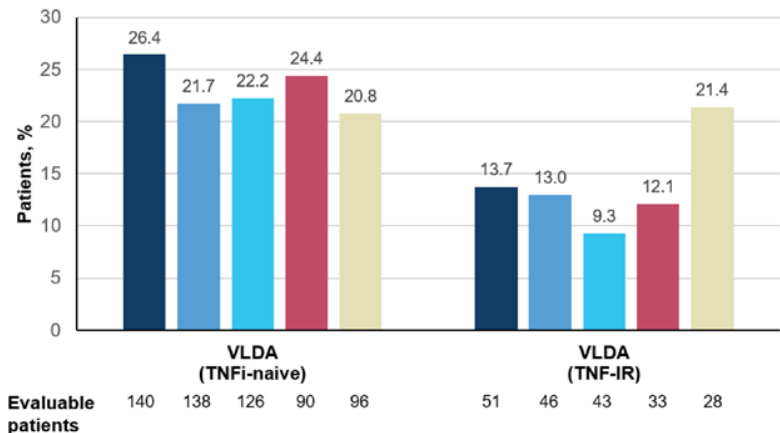

B

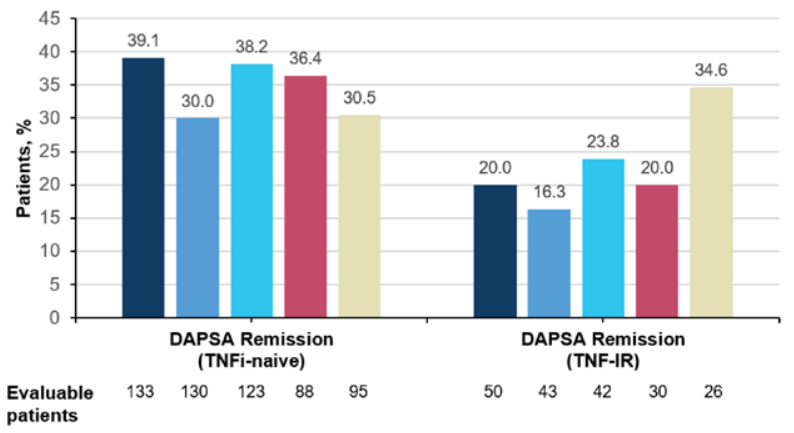

-SEC $300 \mathrm{mg}=$ =SEC $150 \mathrm{mg}$ =SEC $150 \mathrm{mg}$ NL. $=$ PBO - SEC $300 \mathrm{mg}$ =PBO - SEC $150 \mathrm{mg}$

DAPSA, Disease Activity in Psoriatic Arthritis; IR, inadequate responders; NL, no subcutaneous loading dose; PBO, placebo; SEC, secukinumab; VLDA, very low disease activity based on body surface area.
Results: Regardless of previous TNFi exposure, SEC-treated patients achieved several stringent endpoints across PsA domains, including TJC/SJC resolution, resolution of dactylitis/enthesitis, mNAPSI75, and PASI100 at Week 104 (Table 1). TNFi-naive patients generally experienced greater improvements than TNF-IR patients (Table 1 above). Similar trends were observed for achievement of VLDA and DAPSA remission at Week 104 (Figure 1).

Conclusion: SEC treatment resulted in sustained achievement of stringent end points across key PsA manifestations through Week 104 in both TNFi-naive and TNF-IR patients, with generally greater clinical responses among TNFi-naive patients. REFERENCES:

[1] Mease P, et al. Ann Rheum Dis. 2018;77:890-897.

[2] Mease P, et al. Arthritis Rheumatol. 2019;71:(suppl 10) [abstract 1554]. Acknowledgements: This study was funded by Novartis Pharma AG. The authors thank Prasanthi Mandalay, PhD, of ArticulateScience LLC, for providing medical writing support/editorial support, which was funded by Novartis Pharmaceuticals Corporation, East Hanover, NJ, in accordance with Good Publication Practice (GPP3) guidelines (http://www.ismpp.org/gpp3).

Disclosure of Interests: Ana-Maria Orbai Consultant of: Janssen, Eli Lilly, Novartis, Pfizer, and UCB, Grant/research support from: AbbVie, Celgene, Horizon, Janssen, Eli Lilly, and Novartis, M Elaine Husni Consultant of: AbbVie, Amgen, Gilead, Janssen, Eli Lilly, Novartis, Pfizer, Regeneron, and UCB, Grant/research support from: Pfizer, Dafna D Gladman Consultant of: AbbVie, Amgen, Bristol Myers Squibb, Celgene, Galapagos, Gilead, Janssen, Eli Lilly, Novartis, Pfizer, and UCB, Grant/research support from: AbbVie, Amgen, Celgene, Eli Lilly, Novartis, Pfizer, and UCB, Bhumik Parikh Employee of: Novartis Pharmaceuticals Corporation, East Hanover, NJ, USA, Xiangyi Meng Employee of: Novartis Pharmaceuticals Corporation, East Hanover, NJ, USA, Corine Gaillez Employee of: Novartis Pharma AG, Basel, Switzerland, Philip J Mease Speakers bureau: AbbVie, Amgen, Janssen, Eli Lilly, Novartis, Pfizer, and UCB, Consultant of: AbbVie, Amgen, Boehringer Ingelheim, Bristol Myers Squibb, Celgene, Galapagos, Gilead, GlaxoSmithKline, Janssen, Eli Lilly, Novartis, Pfizer, Sun Pharma, and UCB, Grant/research support from: AbbVie, Amgen, Bristol Myers Squibb, Celgene, Gilead, Janssen, Eli Lilly, Novartis, Pfizer, Sun Pharma, and UCB. DOI: 10.1136/annrheumdis-2021-eular.1862

\section{POS1051 SECUKINUMAB IMPROVES PHYSICAL FUNCTION AND INHIBITS STRUCTURAL DAMAGE IN PSA PATIENTS WITH SUSTAINED REMISSION OR LOW DISEASE ACTIVITY: RESULTS FROM A PHASE 3 STUDY}

L. C. Coates ${ }^{1}$, P. J. Mease ${ }^{2}$, D. D. Gladman ${ }^{3}$, S. Navarra ${ }^{4}$, W. Bao ${ }^{5}$, C. Gaillez ${ }^{6}$. ${ }^{1}$ University of Oxford, Nuffield Department of Orthopaedics, Rheumatology and Musculoskeletal Sciences, Oxford, United Kingdom; ${ }^{2}$ Swedish Medical Center/Providence St. Joseph Health and University of Washington, Department of Rheumatology, Seattle, Washington, United States of America; ${ }^{3}$ Toronto Western Hospital, University of Toronto, Schroeder Arthritis Institute, Ontario, Canada; ${ }^{4}$ University of Santo Tomas Hospital, Section of Rheumatology, Manila, Philippines; ${ }^{5}$ Novartis Pharmaceuticals Corporation, Immunology, Hepatology and Dermatology, East Hannover, New Jersey, United States of America; ${ }^{6}$ Novartis Pharma AG, Immunology, Hepatology and Dermatology, Basel, Switzerland

Background: Disease Activity Index for Psoriatic Arthritis (DAPSA) or the minimal disease activity (MDA) are considered for defining remission (REM) or low disease activity (LDA) in secukinumab (SEC) treated patients (pts) with PsA (Psoriatic Arthritis). ${ }^{1}$ Currently, limited SEC data are available on pts with PsA achieving sustained REM in clinical trials or real-world evidence, using these stringent criteria.

Objectives: To report an exploratory analysis on achievement of sustained REM/LDA in pts with PsA treated with SEC and impact on structural outcomes physical function and health-related quality of life (HRQoL) in the FUTURE 5 study (NCT02404350). 
Methods: FUTURE 5 is a randomised, double-blind, placebo-controlled 2-year phase 3 trial in pts with active PsA. ${ }^{2}$ Pts randomised to SEC $150 \mathrm{mg}$ could be escalated to $300 \mathrm{mg}$ from Week (Wk) 52 to 104, based on investigators' judgement. The pts were categorised as either not achieving REM/LDA, achieving it once only or sustained REM/LDA, which was defined as pts who achieved REM/ LDA between Wks 24-52 and maintained the same response at least 2 of the next 6 visits (visit every 8 Wks). Of pts who did not achieve REM/LDA, achieved REM/LDA (VLDA, DAPSA REM, MDA, DAPSA LDA+REM) between Wk 24 and 52 , the relationship between absence of REM/LDA, REM/LDA, sustained REM/ LDA, proportion of pts with non-radiographic progression (assessed using the van der Heijde [mTSS]), physical function (health assessment questionnaire disability index [HAQ-DI]), and short form-36 physical component score [SF-36 PCS] $)^{3}$ were assessed.

Results: In total, 996 pts were randomised to one of 4 treatment groups: SEC $300 \mathrm{mg}$ loading dose (LD; $\mathrm{N}=222)$, SEC $150 \mathrm{mg}$ LD ( $\mathrm{N}=220)$, SEC $150 \mathrm{mg}$ no loading dose ( $\mathrm{NL} ; \mathrm{N}=222)$, and placebo $(\mathrm{N}=332)$. The baseline clinical characteristics were comparable across treatment groups. Majority of pts could achieve either sustained MDA/sustained DAPSA LDA+REM (Figure 1). Pts achieving REM/LDA, whether at one visit or consistently, showed improved physical function and SF36-PCS at Wk $104 .{ }^{3} \mathrm{~A}$ high proportion of pts did not show radiographic progression at Wk 104 irrespective of achievement of REM/LDA category (Table 1).

Conclusion: The majority of patients treated with secukinumab were able to achieve sustained LDA. Sustained LDA/REM was associated with improved HRQoL, physical function and inhibition of structural damage progression. REFERENCES:

[1] Coates LC, et al. J Rheumatol. 2018;46(1):38-42.

[2] Van der Heijde D, et al. Rheumatology. 2020;59(6):1325-1334.

[3] Coates L, et al. [0353]. Arthritis Rheumatol. 2020;72 (suppl 10).

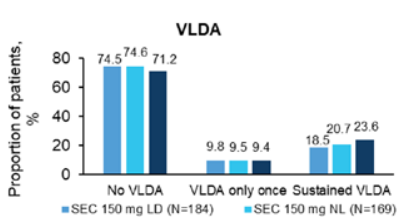


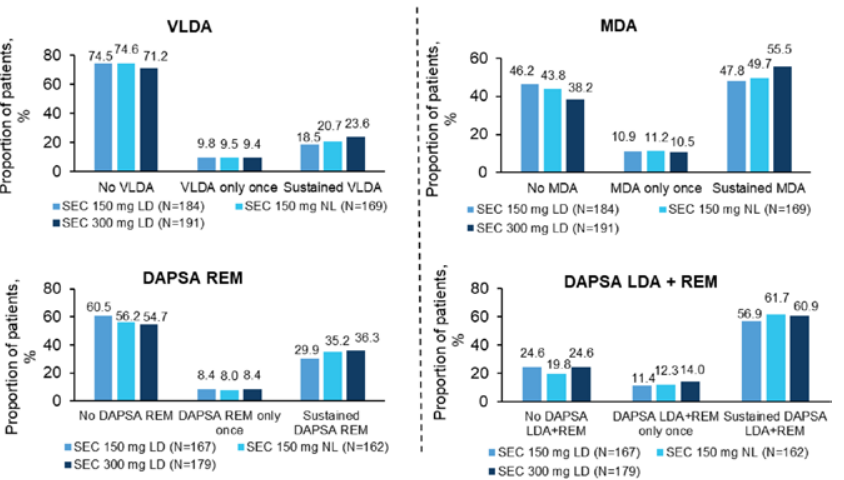

Figure 1. Proportion of patients achieving VLDA/MDA/DAPSA REM/DAPSA REM+LDASustained REM/LDA was defined if the same response was achieved at least 2 out of the next 6 visits (every 8 weeks), respectively. DAPSA, Disease activity in Psoriatic Arthritis; LD, loading dose; LDA, Low Disease Activity; MDA, Minimal Disease Activity; N, number of randomised patients assessed at both Week 24 and 104; NL, without loading dose; REM, remission; SEC, secukinumab; VLDA, Very Low Disease Activity

Table 1. Percentage of vdH-mTSS no progression at Week 104 (change from baseline $\leq 0.5$ ) by REM/LDA and sustained REM/LDA status

\begin{tabular}{|c|c|c|c|c|}
\hline $\begin{array}{l}\text { REM and LDA composite indices, } \\
\text { n (\%) }\end{array}$ & Treatment group & $\begin{array}{l}\text { p No REM/ } \\
\text { LDA }\end{array}$ & $\begin{array}{l}\text { REM/LDA } \\
\text { only once }\end{array}$ & $\begin{array}{l}\text { Sustained } \\
\text { REM/LDA }\end{array}$ \\
\hline \multirow[t]{3}{*}{ MDA } & SEC $150 \mathrm{mg}$ LD & 64 (75.3) & $16(80.0)$ & $76(86.4)$ \\
\hline & SEC $150 \mathrm{mg} \mathrm{NL}$ & $56(75.7)$ & 15 (78.9) & $69(82.1)$ \\
\hline & SEC $300 \mathrm{mg}$ LD & $58(79.5)$ & $19(95.0)$ & $100(94.3)$ \\
\hline \multirow[t]{3}{*}{ VLDA } & SEC $150 \mathrm{mg}$ LD & $108(78.8)$ & 15 (83.3) & 30 (88.2) \\
\hline & SEC $150 \mathrm{mg} \mathrm{NL}$ & 95 (75.4) & $13(81.3)$ & 32 (91.4) \\
\hline & SEC $300 \mathrm{mg}$ LD & $115(84.6)$ & 17 (94.4) & $45(100.0)$ \\
\hline \multirow[t]{3}{*}{ DAPSA REM } & SEC $150 \mathrm{mg}$ LD & 77 (76.2) & 11 (78.6) & 46 (92.0) \\
\hline & SEC $150 \mathrm{mg} \mathrm{NL}$ & 65 (71.4) & $10(76.9)$ & $50(87.7)$ \\
\hline & SEC $300 \mathrm{mg}$ LD & $82(83.7)$ & 14 (93.3) & 63 (96.9) \\
\hline \multirow[t]{3}{*}{ DAPSA LDA + REM } & SEC $150 \mathrm{mg}$ LD & $29(70.7)$ & $16(84.2)$ & $80(84.2)$ \\
\hline & SEC $150 \mathrm{mg} \mathrm{NL}$ & $23(71.9)$ & $15(75.0)$ & $79(79.0)$ \\
\hline & SEC $300 \mathrm{mg}$ LD & $39(88.6)$ & $21(84.0)$ & $97(89.0)$ \\
\hline
\end{tabular}

Sustained REM/LDA was defined if the same response was achieved at least twice out of the next 6 visits (every 8 weeks), respectively. n, number of evaluable patients; vdH-mTSS, van der Heijde- modified total Sharp score

Disclosure of Interests: Laura C Coates Consultant of: Abbvie, Amgen, Biogen, Boehringer Ingelheim, Celgene, Galapagos, Gilead, Janssen, Lilly, Novartis, Pfizer and UCB, Grant/research support from: Abbvie, Celgene, Lilly, Novartis and Pfizer, Philip J Mease Speakers bureau: AbbVie, Amgen, Janssen, Lilly,
Novartis, Pfizer and UCB, Consultant of: AbbVie, Amgen, BMS, Boehringer Ingelheim, Galapagos, Celgene, Genentech, Gilead, Janssen, Lilly, Novartis, Pfizer, SUN Pharma, and UCB, Grant/research support from: AbbVie, Amgen, BMS, Celgene, Galapagos, Gilead, Janssen, Lilly, Novartis, Pfizer, SUN, and UCB, Dafna D Gladman Consultant of: Abbvie, Amgen, BMS, Celgene, Eli Lilly, Gilead, Galapagos, Janssen, Novartis, Pfizer and UCB, Grant/research support from: Abbvie, Amgen, BMS, Celgene, Eli Lilly, Gilead, Galapagos, Janssen, Novartis, Pfizer and UCB, Sandra Navarra Speakers bureau: Pfizer, Novartis, Astra-Zeneca, Janssen, Lilly, and Astellas, Consultant of: Pfizer, Novartis, Astra-Zeneca, Janssen, Lilly, and Astellas, Weibin Bao Shareholder of: Novartis, Employee of: Novartis, Corine Gaillez Shareholder of: Novartis and BMS, Employee of: Novartis.

DOI: 10.1136/annrheumdis-2021-eular.1971

\section{POS1052 PSORIATIC ARTHRITIS AND OBESITY IMPACT DRUG PERSISTENCE IN USTEKINUMAB-TREATED PATIENTS WITH PSORIASIS IN THE BRITISH ASSOCIATION OF DERMATOLOGISTS BIOLOGIC AND IMMUNOMODULATORS REGISTER (BADBIR): A 10-YEAR FOLLOW-UP STUDY}

A. Ogdie ${ }^{1}$, W. Tillett ${ }^{2}$, A. Passey ${ }^{3}$, P. Gorecki ${ }^{4} .{ }^{1}$ University of Pennsylvania, Perelman School of Medicine, Philadelphia, United States of America; ${ }^{2}$ Royal National Hospital for Rheumatic Diseases, Rheumatology, Bath, United Kingdom; ${ }^{3}$ Janssen Real World Evidence, HEMAR EMEA, High Wycombe, United Kingdom; ${ }^{4}$ Janssen, Medical Affairs, High Wycombe, United Kingdom

Background: Up to $80 \%$ of patients with psoriatic arthritis (PsA) have comorbid psoriasis (PsO). ${ }^{1}$ However, data on the impact of comorbid PsA on treatment persistence in PsO patients are limited with mixed findings. ${ }^{2-4}$ Other factors have been implicated in predicting response to treatment, including obesity, which is associated with PsA and has demonstrated a varying effect on biologic persistence..$^{2,3,5,6}$

Objectives: The primary objective of this study was to evaluate whether comorbid PsA and obesity impact ustekinumab (UST) persistence in PsO patients using the British Association of Dermatologists Biologic and Immunomodulators Register (BADBIR). Additionally, the effect of line of therapy was investigated. Methods: This retrospective observational study used data from PsO patients receiving UST in the BADBIR (first enrolled 07/2009; 10/2020 data cut-off). Time to discontinuation (TTD) was defined as time from treatment start date until treatment stop date, censoring for loss to follow-up where patients are lost to follow-up or active in the registry without a recorded treatment stop date. KaplanMeier survival analysis was used to estimate probability of discontinuation over time and median TTD. Patients were stratified by PsA diagnosis (recorded as a comorbidity at enrolment) and prior biologic experience (history of treatment with $\geq 1$ other biologic). The log-rank test was used to compare persistence among groups. Hazard ratios (HRs), confidence intervals $(\mathrm{Cl})$ and $p$-values for effect of obesity, PsA status and prior biologic exposure on TTD were generated using Cox proportional hazards regression.

Results: Univariate analysis found that median TTD was shorter for patients with comorbid PsO and PsA (5.04 years; $n=585$ ) vs. patients with PsO alone (7.19 years; $n=2698 ; p<0.0001$ ). Biologic-experienced patients with comorbid $\mathrm{PsO}$ and PsA $(\mathrm{n}=292)$ had a significantly higher likelihood of discontinuation than any other group, with a median TTD of 3.84 years $(p<0.0001$; Figure 1). In

Fig. 1: Drug survival in patients with $\mathrm{PsO}$ treated with UST, stratified by presence of comorbid PsA and prior biologic experience.

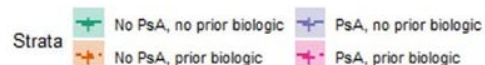
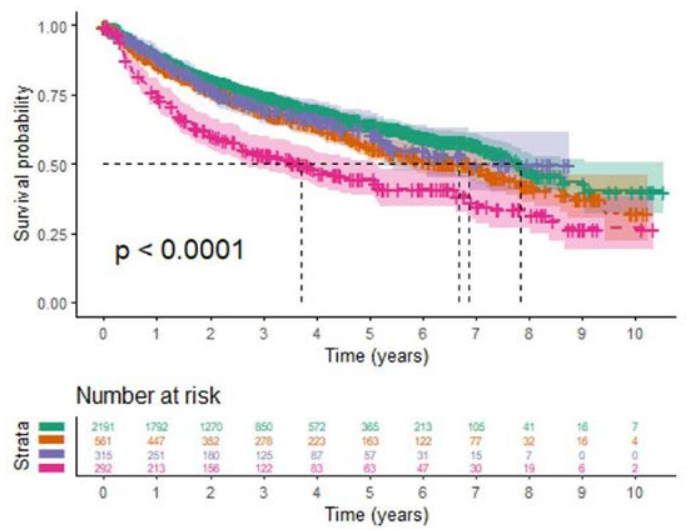

p-value for drug survival probability across all groups. PsA, psoriatic arthritis; PsO, psoriasis; UST, ustekinumab. 